PUSTABIBLIA: Journal of Library and Information Science

ISSN 2549-3493 (Print); ISSN 2549-3868 (Online)

DOI: http://dx.doi.org/10.18326/pustabiblia.v4i2.307-324

SK Dirjen Risbang-Kemristekdikti No 23/E/KPT/2019 (Peringkat 4 SINTA)

\title{
Analisis Pemanfaatan E-Resources oleh Mahasiawa Pascasarjana IAIN Salatiga
}

\author{
Itmamudin \\ IAIN Salatiga \\ itmamudin79@gmail.com \\ Diajukan: 18-11-2020; Direview: 19-11-2020; Diterima: 19-11-2020; 19-11-2020
}

\begin{abstract}
In accordance with the National Education System Law of 2003 Number 20 paragraph 3. Higher education has the task of carrying out education, research and community service or what is commonly known as the Tri Dharma of Education. Higher education libraries have an information function, namely facilitating access to students and the academic community to obtain information to support the Tri Dharma of Higher Education. Libraries are responsible for compiling collections or information, both printed and non-printed (digital). Non-print access is required because of the habit of reading digital documents. The digital sources served by the IAIN Salatiga library currently are electronic journals including The MIT Press, JStor, and Emerald Insight, while the IAIN Salatiga library e-books subscribes to Ebscohost and Pustabiblia. This research examines the use of e-resources by IAIN Salatiga postgraduate students. The use of e-resources referred to in this study refers to the Techonology Acceptance Model (TAM) theory developed by Davis (1986). This research is a quantitative study with a correlation approach. The research instrument used in this study was a questionnaire. There are 3 tests, the first has no effect, namely information literacy on the ease of use of e-resources. Two other tests show an effect. First, information literacy has an effect on perceived usefulness or perceptions of the usefulness of e-resources. It can be concluded that students who have information literacy perceive that e-resources from the IAIN Salatiga Library are useful. Second, information literacy affects actual to use or direct use of e-resources. IAIN Salatiga students who have information literacy skills will use the e-resources subscribed to by the IAIN Salatiga Library.
\end{abstract}

Keywords: E-resource, library, Digital Library 


\begin{abstract}
Abstrak
Sesuai Undang-undang Sistem Pendidikan Nasional Tahun 2003 Nomor 20 ayat 3. Perguruan tinggi mempunyai tugas menjalankan Pendidikan, penelitian dan pengabdian kepada masyarakat atau yang biasa dengan istilah Tri Dharma Pendidikan. Perpustakaan perguruan inggi memiliki fungsi informasi yaitu memfasilitasi akses mahasiswa maupun civitas akademika untuk memperoleh informasi guna menunjang Tri Dharma Perguruan tinggi. Perpustakaan bertanggung jawab untuk menghimpun koleksi atau informasi baik berbentuk cetak maupun non cetak (digital). Akses non-cetak diperlukan karena adanya pola kebiasaan membaca dokumen digital. sumber digital yang dilayankan oleh perpustakaan IAIN Salatiga saat ini adalah jurnal elektronik diantaranya The MIT Press, JStor, dan Emerald Insight, sedangkan untuk e-book perpustakaan IAIN Salatiga melanggan Ebscohost dan Pustabiblia Penelitian ini mengkaji mengenai pemanfaatan e-resources oleh mahasiswa pascasarjana IAIN Salatiga. Pemanfaatan e-resources yang dimaksudkan dalam penelitian ini mengacu teori Techonology Acceptance Model (TAM) yang dikembangkan oleh Davis (1986). Penelitian ini merupakan penelitian kuantitatif dengan pendekatan korelasi. Instrumen penelitian yang akan digunakan dalam penelitian ini adalah kuesioner. Terdapat 3 pengujian, pertama tidak memiliki pengaruh yaitu literasi informasi terhadap kemudahan penggunaan e-resources. Dua pengujian lainnya menunjukkan adanya pengaruh. Pertama, literasi informasi berpengaruh terhadap perceived of usefulness atau persepsi mengenai kegunaan / manfaat e-resources. Dapat disimpulkan bahwa mahasiswa yang memiliki literasi informasi berpersepsi bahwa e-resources dari Perspustakaan IAIN Salatiga bermanfaat. Kedua, literasi informasi berpengaruh terhadap actual to use atau penggunaan e-resources secara langsung. Mahasiswa IAIN Salatiga yang memiliki kemampuan literasi informasi akan menggunakan e-resources yang dilanggan Perpustakaan IAIN Salatiga.
\end{abstract}

Kata Kunci: E-resource, Perpustakaan, Perpustakaan digital

\title{
A. LATAR BELAKANG
}

Sesuai dengan Undang-Undang Sistem Pendidikan Nasional tahun 2003 pasal 20 ayat 3. Perguruan tinggi mempunyai tugas menjalankan pendidikan, penelitian dan pengabdian kepada masyarakat. Tiga tugas wajib ini dikenal dengan istilah Tri Dharma perguruan tinggi. Perpustakaan perguruan tinggi yang merupakan bagian dari perguruan tinggi berperan 
menyediakan layanan informasi bagi akademisi. Perpustakaan perguruan tinggi mempunyai peran yang strategis untuk menunjang peningkatan kualitas proses pembelajaran melalui informasi yang disediakannya.

Perpustakaan perguruan tinggi memiliki fungsi informasi yaitu memfasilitasi akses informasi mahasiswa sesuai bidang yang dicakupi perguruan tinggi maupun informasi lain untuk memperbanyak pilihan sumber informasi. Dalam mendukung kegiatan penelitian, perpustakaan bertanggungjawab menyediakan sumber-sumber informasi atau referensi yang relevan dengan kebutuhan penelitian. Perpustakaan perguruan tinggi sudah selayaknya menyediakan akses sumberdaya informasi baik tercetak maupun digital. Akses terhadap sumber daya digital mulai diminati karena adanya pergeseran pola kebiasaan membaca dokumen ke digital.

Salah satu sumber digital yang dilayankan oleh perpustakaan IAIN Salatiga saat ini adalah jurnal elektronik diantaranya The MIT Press, JStor, dan Emerald Insight, sedangkan untuk e-book perpustakaan IAIN Salatiga melanggan Ebscohost dan Pustabiblia yang berisi berbagai macam buku elektronik yang memberikan keakuratan informasi dan kecepatan dalam mengaksesnya. Jurnal sendiri memuat publikasi temuan atau hasil penelitian ilmiah berupa artikel ilmiah berbagai bidang ilmu pengetahuan. Akses jurnal elektronik dengan perangkat digital dapat menunjang kebutuhan referensi perkuliahan, maupun penelitian untuk menyusun karya ilmiah, skripsi, tesis dan disertasi. Jurnal elektronik bisa diakses kapan saja, dalam waktu yang bersamaan tanpa perlu bergantian seperti jurnal tercetak. Kemudahan akses informasi menjadi kunci utama demi terwujudnya layanan informasi yang memuaskan.

Keberadaan eresources dalam sebuah perguruan tinggi sudah menjadi sebuah keharusan sebagai referensi penelitian yang memuat berbagai isu terkini dari hasil-hasil penelitian dan koleksi digital yang mampu memberikan solusi bagi keterbatasan ruang dan waktu dalam mengaksesnya. Demikian pula dengan perpustakaan IAIN Salatiga yang memiliki layanan jurnal elektronik dan koleksi buku digital untuk memenuhi kebutuhan informasi seluruh civitas akademika secara lebih komprehensif, lengkap, praktis, cepat dalam mengakses dan tidak terbatas ruang dan waktu. 
Mahasiswa sangat membutuhkan sumber informasi bagi penelitianya. Lebih khusus mahasiswa pascasarjana yang lebih banyak membutuhkan banyak jurnal ilmiah untuk penelitianya. Menurut penelitian yang telah dilakukan oleh Nusantari (2012) dan Katabalwa (2016) menyatakan bahwa mahasiswa pascasarjana menjadi pengguna yang lebih aktif dalam memanfaatkan e-resources.

Berdasarkan hal itu, maka peneliti ingin meneliti lebih jauh mengenai pemanfaatan e-resources yang dilanggan perpustakaan IAIN Salatiga oleh mahasiswa pascasarjana dan sebagai upaya dalam mengambil kebijakan dalam rangka peningkatan layanan kepada pemustaka.

\section{B. RUMUSAN MASALAH}

1. Bagaimana pemanfaatan e-resource oleh mahasiswa Pascasarjana IAIN Salatiga?

\section{TUJUAN DAN SIGNIFIKANSI}

1. Penelitian ini bertujuan untuk:

Untuk mengetahui pemanfaatan e-resources yang dimiliki perpustakaan IAIN Salatiga oleh mahasiswa pascasarjana IAIN Salatiga

2. Signifikansi Penelitian :

a. Bagi UPT Perpustakaan IAIN Salatiga : hasil penelitian ini dapat dijadikan pijakan dalam menentukan langkah untuk membuat kebijakan tentang pemanfaatan $e$-resources oleh mahasiswa

b. Bagi lembaga IAIN Salatiga : Dengan melakukan evaluasi terhadap pemanfaatan e-resources ini dapat digunakan sebagai dasar untuk membuat kebijakan tentang anggaran perpustakaan, apakah akan dilanjutkan dengan menaikkan anggaran atau tidak.

\section{TELAAH PUSTAKA}

Penelitian tentang penggunaan e-journal sebagai rujukan pernah dilakukan oleh Anastasia Tri Susiati (2011) dengan judul penelitian 
"Pemanfaatan Jurnal Elektronik di Perpustakaan Universitas Atma Jaya Yogyakarta". Tujuan dari penelitian ini adalah Mengetahui pemanfaatan jumal elektronik dan meneliti faktor-faktor yang mempengaruhi mahasiswa memanfaatkan jurnal elektronik berdasarkan teori Technology Acceptance Model (TAM) yang dikembangkan oleh Davis (1939). Metode penelitian yang digunakan adalah kuantitatif dengan survey yang dibagikan kepada 100 orang mahasiswa. Faktor-faktor complexity, user training, computer self efficacy, perceived usefulness, perceived ease of use, intention to use dan actual to use, merupakan faktor-faktor yang valid dalam penerimaan mahasiswa terhadap pemanfaatan jurnal elektronik dengan pendekatan TAM. Perceived ease of use tidak berpengaruh terhadap perceived usefulness menunjukkan bahwa jumal elektronik mudah untuk digunakan, tetapi tidak mempengaruhi persepsi mahasiswa bahwa manfaatnya akan besar pada prestasi kerjanya. Hal ini menunjukkan bahwa kesadaran penggunaan jurnal elektronik masih bersifat mandatory untuk memenuhi syarat tertentu dan belum menunjukkan pemanfaatan yang bersifat sukarela karena sudah merasakan manfaatnya.

Penelitian sejenis lainnya dilakukan oleh Kurnia Sholihah pada tahun 2016 dengan judul Analisis Literasi digital: Studi Pemanfaatan Jurnal Elektronik Oleh Mahasiswa Magister Manajemen di Perpustakaan Universitas Kristen Satya Wacana Salatiga. Metode penelitian yang dilakukan adalah observasi, dokumentasi dan kuisioner dengan populasi sampel yang digunakan adalah mahasiswa magister manajemen UKSW, menujukkan bahwa presentase terbesar karakteristik responden dalam memanfaatkan jurnal elektronik di Perpustakaan UKSW Salatiga: laki-laki 60\%, berusia 2029 tahun sebesar 80\%, menggunakan smartphones sebesar 31\%, frekuensi berinternet setiap hari sebesar $60 \%$. Tingkat literasi berdasarkan aspek teknis dikategorikan memiliki tingkat yang sangat tinggi, yaitu 4,22, berdasrakan aspek kognitif dikategorikan tinggi yaitu 4,178, dan berdasarkan aspek sosial dikategorikan tinggi yaitu 4,124. Terdapat berapa indikator yang memiliki rata-rata terendah yaitu aspek frekuensi pemanfaatan jurnal elektronik mendapat nilai rata-rata paling rendah yaitu 3,43, aspek kemampuan berpikir kritis mendapat nilai rata-rata paling rendah yaitu 3,64, aspek kemampuan 
mengatur privasi online mendapat nilai rata-rata paling rendah yaitu 3,9.

Kemudian penelitian sejenis lainnya dilakukan oleh Anajoyce Samuel Katabalwa pada tahun 2016 dengan judul "Use of electronic journalresources by postgraduate students at the Universityof Dar es Salaam". Tujuan dari penelitian ini adalah menilai penggunaan sumber daya jurnal elektronik di Universitas Dar es Salaam dengan metode penelitian yang digunakan yaitu kuesioner untuk 100 mahasiswa pascasarjana dan wawancara untuk 6 pustakawan referensi. Hasilnya adalah mayoritas mahasiswa menggunakan sumber daya jurnal elektronik untuk berbagai keperluan seperti mengerjakan tugas, proposal penelitian, menulis laporan penelitian. Kendala yang dihadapi dalam mengakses jurnal elektronik adalah ketika terjadi pemadaman listrik, bandwith yang kurang memadai, kecepatan akses yang lambat, ketidakmampuan untukmengakses sumber daya dari rumah, kurangnya pelatihan, kurangnya kesadaran, akses terbatas ke komputer dan kesulitan dalam pencarian.

Perbandingan penelitian sebelumnya dengan penelitian ini

\begin{tabular}{|c|c|c|c|c|c|}
\hline No. & Aspek Pembeda & Penelitian 1 & Penelitian 2 & Penelitian 3 & Penelitian ini \\
\hline 1. & $\begin{array}{l}\text { Peneliti dan ta- } \\
\text { hun penelitian }\end{array}$ & $\begin{array}{l}\text { Anastasia Tri } \\
\text { Susiati (2011) }\end{array}$ & $\begin{array}{l}\text { Kurnia Sholihah } \\
\text { (2016) }\end{array}$ & $\begin{array}{l}\text { Anajoyce Sam- } \\
\text { uel Katabalwa } \\
(2016)\end{array}$ & $\begin{array}{l}\text { Itmamudin } \\
(2020)\end{array}$ \\
\hline 2. & Judul Penelitian & $\begin{array}{l}\text { Pemanfaatan } \\
\text { Jurnal Elektronik } \\
\text { di Perpustakaan } \\
\text { Universitas Atma } \\
\text { Jaya Yogyakarta }\end{array}$ & $\begin{array}{l}\text { Analisis Literasi } \\
\text { digital: Studi } \\
\text { Pemanfaatan } \\
\text { Jurnal Elektronik } \\
\text { Oleh Maha- } \\
\text { siswa Magister } \\
\text { Manajemen di } \\
\text { Perpustakaan } \\
\text { Universitas } \\
\text { Kristen Satya } \\
\text { Wacana Salatiga }\end{array}$ & $\begin{array}{l}\text { Use of electronic } \\
\text { journal resources } \\
\text { by postgraduate } \\
\text { students at the } \\
\text { University of } \\
\text { Dar es Salaam }\end{array}$ & $\begin{array}{l}\text { Analisis } \\
\text { Pemanfaatan } \\
\text { E-resource oleh } \\
\text { Mahasiswa Pas } \\
\text { casarjana IAIN } \\
\text { Salatiga }\end{array}$ \\
\hline 3. & $\begin{array}{l}\text { Tempat pene- } \\
\text { litian }\end{array}$ & $\begin{array}{l}\text { Perpustakaan } \\
\text { Universitas Atma } \\
\text { Jaya Yogyakarta }\end{array}$ & $\begin{array}{l}\text { Perpustakaan } \\
\text { Universitas } \\
\text { Kristen Satya } \\
\text { Wacana Salatiga }\end{array}$ & $\begin{array}{l}\text { University of } \\
\text { Dar es Salaam }\end{array}$ & IAIN Salatiga \\
\hline
\end{tabular}




\begin{tabular}{|c|c|c|c|c|c|}
\hline No. & Aspek Pembeda & Penelitian 1 & Penelitian 2 & Penelitian 3 & Penelitian ini \\
\hline 4. & $\begin{array}{l}\text { Tujuan peneli- } \\
\text { tian }\end{array}$ & $\begin{array}{l}\text { Mengetahui } \\
\text { pemanfaatan } \\
\text { jumal elektronik } \\
\text { dan meneliti } \\
\text { faktor-faktor } \\
\text { yang mempenga- } \\
\text { ruhi mahasiswa } \\
\text { memanfaatkan } \\
\text { jurnal elektronik } \\
\text { berdasarkan } \\
\text { teori Technol- } \\
\text { ogy Acceptance } \\
\text { Model (TAM) } \\
\text { yang dikem- } \\
\text { bangkan oleh } \\
\text { Davis (1939) }\end{array}$ & $\begin{array}{l}\text { Mengetahui } \\
\text { karakteristik } \\
\text { responden dan } \\
\text { melakukan } \\
\text { analisis literasi } \\
\text { digital maha- } \\
\text { siswa Magister } \\
\text { Manajemen } \\
\text { UKSW dalam } \\
\text { memanfaatkan } \\
\text { jurnal elektronik } \\
\text { di Perpustakaan } \\
\text { UKSW Salatiga } \\
\text { berdasarkan } \\
\text { aspek teknis, } \\
\text { kognitif, dan } \\
\text { sosial. }\end{array}$ & $\begin{array}{l}\text { Menilai peng- } \\
\text { gunaan sumber } \\
\text { daya jurnal } \\
\text { elektronik di } \\
\text { Universitas Dar } \\
\text { es Salaam }\end{array}$ & $\begin{array}{l}\text { Mengetahui } \\
\text { pemanfaatan } \\
\text { e-resources yang } \\
\text { dimiliki per- } \\
\text { pustakaan IAIN } \\
\text { Salatigaoleh } \\
\text { mahasiswa pas- } \\
\text { casarjana IAIN } \\
\text { Salatiga }\end{array}$ \\
\hline 5. & $\begin{array}{l}\text { Metode pene- } \\
\text { litian }\end{array}$ & Kuantitatif & $\begin{array}{l}\text { Kuantitatif den- } \\
\text { gan kuisioner, } \\
\text { observasi, doku- } \\
\text { mentasi }\end{array}$ & $\begin{array}{l}\text { Kuantitatif } \\
\text { (kuesioner un- } \\
\text { tuk mahasiswa } \\
\text { dan wawa- } \\
\text { ncara untuk } \\
\text { pustakawan } \\
\text { referensi) }\end{array}$ & Kuantitatif \\
\hline 6. & Hasil penelitian & $\begin{array}{l}\text { Faktor-faktor } \\
\text { complexity, } \\
\text { user training, } \\
\text { computer self ef- } \\
\text { ficacy, perceived } \\
\text { usefulness, } \\
\text { perceived ease of } \\
\text { use, intention to } \\
\text { use dan actual to } \\
\text { use, merupakan } \\
\text { faktor-faktor } \\
\text { yang valid dalam } \\
\text { penerimaan ma- } \\
\text { hasiswa terhadap } \\
\text { pemanfaatan } \\
\text { jurnal elektronik } \\
\text { dengan }\end{array}$ & $\begin{array}{l}\text { Presentase } \\
\text { karakteristik } \\
\text { responden } \\
\text { memanfaatkan } \\
\text { jurnal elektronik } \\
\text { di Perpustakaan } \\
\text { UKSW Salatiga: } \\
\text { laki-laki 60\%, } \\
\text { usia 20-29 tahun } \\
80 \% \text {, mengguna- } \\
\text { kan smartphones } \\
31 \% \text {, frekuensi } \\
\text { berinternet se- } \\
\text { tiap hari } 60 \% \text {. } \\
\text { Tingkat literasi } \\
\text { berdasarkan as- } \\
\text { pek teknis }\end{array}$ & $\begin{array}{l}\text { mayoritas } \\
\text { mahasiswa } \\
\text { menggunakan } \\
\text { sumber daya } \\
\text { jurnal elek- } \\
\text { tronik untuk } \\
\text { berbagai keper- } \\
\text { luan seperti } \\
\text { mengerjakan } \\
\text { tugas, pro- } \\
\text { posal penelitian, } \\
\text { menulis laporan } \\
\text { penelitian. } \\
\text { Kendala yang } \\
\text { dihadapi dalam } \\
\text { mengakses jur- } \\
\text { nal elektronik }\end{array}$ & \\
\hline
\end{tabular}




\begin{tabular}{lllll}
\hline No. Aspek Pembeda & \multicolumn{1}{c}{ Penelitian 1 } & \multicolumn{1}{c}{ Penelitian 2 } & \multicolumn{1}{c}{ Penelitian 3 } & Penelitian ini \\
\hline pendekatan & dikategorikan & adalah ketika & - \\
TAM. Perceived & memiliki tingkat & terjadi pema- \\
ease of use tidak & yang sangat & daman listrik, & \\
berpengaruh ter- & tinggi 4,22, & bandwith yang & \\
hadap perceived & berdasarkan & kurang mema- \\
usefulness me- & aspek kognitif & dai, kecepatan \\
nunjukkan bah- & dikategorikan & akses yang \\
wa jumal elek- & tinggi yaitu & lambat, keti- \\
tronik mudah & 4,178, berdasar- & dakmampuan \\
untuk diguna- & kan aspek sosial & untukmengak- \\
kan, tetapi tidak & dikategorikan & ses sumber daya \\
mempengaruhi & tinggi yaitu & dari rumah, \\
persepsi maha- & 4,124. indikator & kurangnya pela- & \\
siswa bahwa & yang memiliki & tihan, kurang- \\
manfaatnya akan & rata-rata teren- & nya kesadaran, \\
besar pada pres- & dah yaitu frekue- & akses terbatas ke \\
tasi kerjanya. Hal & nsi pemanfaatan & komputer dan \\
ini menunjukkan & jurnal elektronik & kesulitan dalam & \\
bahwa kesadaran & mendapat nilai & pencarian. \\
penggunaan & rata-rata paling & \\
jurnal elektronik & rendah 3,43, as- & \\
masih bersifat & pek kemampuan & \\
mandatory un- & berpikir kritis & \\
tuk memenuhi & mendapat nilai & \\
syarat terten- & rata-rata rendah & \\
tu dan belum & yaitu 3,64, & \\
menunjukkan & kemampuan & \\
pemanfaatan & mengatur privasi & \\
yang bersifat & online mendapat & \\
sukarela karena & nilai rata-rata & \\
sudah merasa- & rendah yaitu 3,9. & \\
kan manfaatnya. & & \\
& & & \\
\hline
\end{tabular}

\section{E. KERANGKA TEORI}

Penelitian ini mengkaji mengenai pemanfaatan e-resources oleh mahasiswa pascasarjana IAIN Salatiga. Pemanfaatan e-resources yang dimaksudkan dalam penelitian ini mengacu teori Techonology Acceptance Model (TAM) yang dikembangkan oleh Davis (1986). 


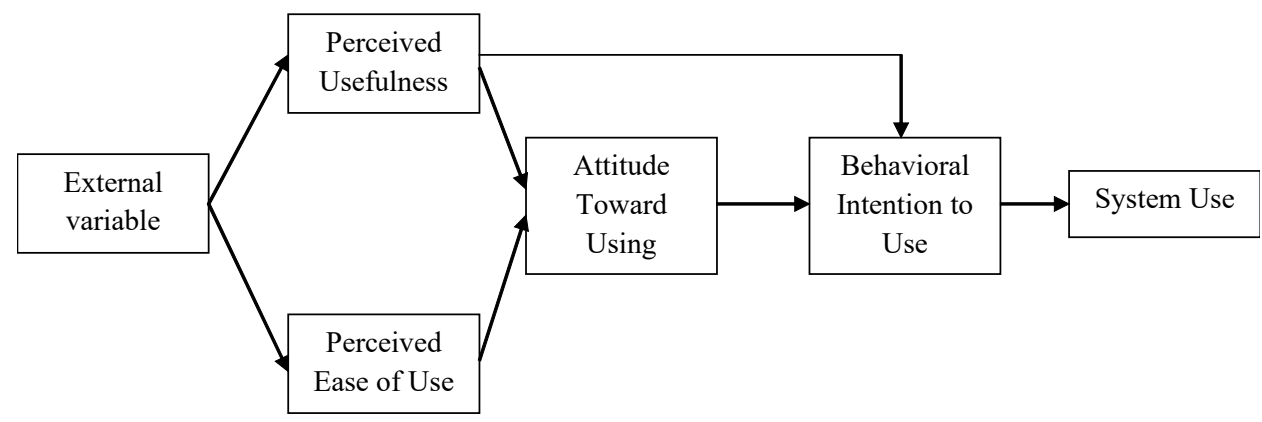

Teori Techonology Acceptance Model (TAM)

Berdasarkan teori tersebut peneliti mengajukan konsep penelitian sebagai berikut:

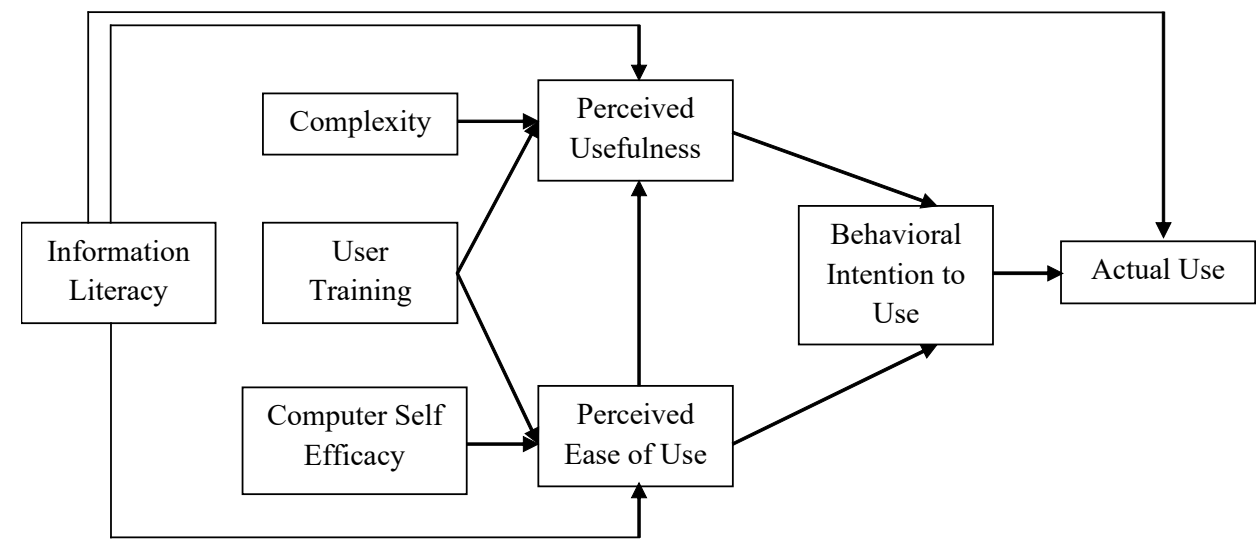

\section{Model penelitian yang diusulkan}

Penelitian ini mengacu teori pada Techonology Acceptance Model (TAM) yang sudah dikembangkan oleh Susanti (2011). Perbedaan signifikan adalah dengan adanya penambahan variabel ekternal berupa information literacy. Information literacy dipilih karena berdasarkan hasil penelitian Susanti (2011: 22) menekankan untuk kegiatan user training tidak hanya menjelaskan teknis penggunaan tetapi juga literasi informasi. Model literasi informasi yang digunakan dalam penelitian ini adalah The Seven Pillars 
of Information Literacy. Model ini diambil karena terdapat keterampilan teknologi informasi (Sulistyo-Basuki, 2013), yang mana sesuai dengan penelitian tentang e-resources.

\section{F. METODE PENELITIAN}

\section{Jenis dan Pendekatan penelitian}

Penelitian ini merupakan penelitian kuantitatif dengan pendekatan korelasi. Penelitian kuantitatif menurut (Sugiyono, 2017: 15) adalah penelitian yang berlandaskan pada filsafat positivism, digunakan untuk meneliti pada populasi atau sampel tertentu, teknik pengambilan sampel umumnya dilakukan secara random, pengumpulan data menggunakan instrument penelitian, analisis data bersifat kuantitatif atau statistik degan tujuan meguji hipotesis yang telah ditetapkan. Sedangkan penelitian korelasi menurut Sulistyo-Basuki $(2006,114)$ adalah penelitian yang disusun untuk mengukur peluang hubungan antara dua variable atau lebih yang dikorelasikan. Pendekatan korelasi ini digunakan untuk mengukur pengaruh literasi informasi dengan pemanfaatan e-resources IAIN Salatiga.

\section{Variabel Penelitian}

Variabel adalah segala sesuatu yang berbentuk apa sajayang ditetapkan oleh peneliti untuk dipelajari sehingga diperoleh informasi tentanghal tersebut, kemudian ditarik kesimpulan (2017 : 60). Dalam penelitian ini variabel yang ditetapkan adalah sebagai berikut:

1. information literacy

2. perceived ease of use

3. perceived usefulness

4. actual to use

\section{Hipotesis Penelitian}

Hipotesis pada dasarrnya diartikan sebagaijawaban sementara terhadap rumusan masalah penelitian (Sugiyono, 2017:159).Hipotesis pada penelitian ini adalah sebagai berikut: 
1. Terdapat pengaruh information literacy terhadap perceived ease of use

2. Terdapat pengaruh information literacy terhadap perceived usefulness

3. Terdapat pengaruh information literacy terhadap actual to use

\section{Populasi dan Sampel}

Menurut Sugiyono (2017: 117) populasi adalah wilayah generalisasi yang terdiri atas objek atau subjek yang mempunyai kualitas dan karakteristik tertentu yang ditetapkan oleh peneliti untuk dipelajari dan kemudian di tarik kesimpulannya.Populasi dalam penelitian ini adalah mahasiswa pascasarjana IAIN Salatiga yang masih aktif, yaitu berjumlah 239 (Pangkalan Data Pendidikan Tinggi Kementerian Riset, Teknologi dan Pendidikan Tinggi, 2019).

Sedangkan sampel adalah bagian dari jumlah dan karakteristik yang dimiliki oleh populasi tersebut (Sugiyono, 2017 : 118). Teknik pengambilan sampel pada penelitian ini adalah incidental sampling. Menurut Sugiyono $(2011,85)$, teknik sampling ini adalah menjadikan siapa saja yang kebetulan bertemu dengan peneliti dan sesuai dengan kriteria maka dijadikan sampel. Implementasi dari teknik ini adalah peneliti membuat kusioner secara online dan menyebarluaskan kepada mahasiswa Pascasarjana IAIN Salatiga. Teknik ini diambil karena situasi saat ini yang kurang mendukung peneliti untuk bertemu langsung dengan mahasiswa.

Teknik penentuan besarnya sampel dalam penelitian ini menggunakan rumus slovin (Sevila, 1993) yaitu:

$$
n=\frac{N}{1+N \cdot e^{2}}
$$

Dimana:

$n$ = Jumlah sampel

$\mathrm{N}=$ Jumlah populasi

e $=$ Presentase toleransi kelonggaran ketidaktelitian

Berdasarkan rumus slovin di atas dan dengan toleransi kelonggaran ketidaktelitian sebesar 10\%, maka didapat jumlah sampel sebagai berikut: 


$$
n=\frac{239}{1+239 \cdot\left(0,1^{2}\right)}
$$

Berdasarkan perhitungan di atas didapat hasil 70.5 dan dibulatkan menjadi 71 mahasiswa untuk memudahkan penghitungan.

\section{Data dan Sumber Data}

Sumber data penelitian yaituasal perolehan data penelitian, perlu dijelaskan, primer maupun sekunder (Wirartha, 2006:35). Pada penelitian ini sumber data yang digunakan terbagi menjadi:

a. Sumber data primer, yaitu data yang dikumpulkan langsung dari sumber pertama. Sumber data primer penelian ini adalah kuesioner yang dibagikan langsung kepada mahasiswa pascasarjana IAIN Salatiga.

b. Sumber data sekunder, yaitu, data yang dikumpulkan oleh peneliti sebagai penunjang sumber data primer. Sumber data sekunder dalam penelitian ini adalah penelitian sebelumnya mengenai penggunaan e-resources.

\section{Metode Pengumpulan data}

Pengumpulan data merupakan hal yang penting dalam sebuah penelitian. Pengumpulan data adalah bagaimana peneliti menentukan metode setepat - tepatnya untuk memperoleh data, kemudian disusul dengan cara-cara menyusunalat pembantunya atau instrument (Arikunto, 2010: 265). Pengumpulan data dalam penelitian ini menggunakan metode survei dengan kuesioner. Kuesioner merupakan cara yang efektif untuk mengumpulkan informasi dalam mengukur perilaku, sikap, dan pendapat dari responden. Kuesioner memberikan kesempatan bagi responden untuk berpikir terlebih dahulu sebelum memberikan jawaban pertanyaan yang diberikan, sehingga jawaban yang terkumpul bisa lebih merepresentasikan apa yang dipikirkan oleh responden. Banyak ditemui dalam penelitian perpustakaan, survei dengan kuesioner digunakan untuk mengestimasi frekuensi dan pola pemanfaatan koleksi, relevansi koleksi, perspektif dan preferensi pengguna terhadap koleksi dan atau layanan pengguna (Covey dalam Nusantari, 2012:30). 


\section{Instrumen Penelitian}

Instrumen pengumpulan data adalah alat bantu yang dipilih dan digunakan oleh peneliti dalam kegiatannya mengumpulkan data agar kegiatan tersebut menjadi sistematis dan dipermudah(Arikunto, 2010:265). Instrumen penelitian yang akan digunakan dalam penelitian ini adalah kuesioner.Kuesioner adalah teknik pengumpulan data yang dilakukan dengan caramemberi seperangkat pertanyaan tertulis kepada responden untuk dijawabnya (Sugiyono, 2017: 142). Kuesioner dibuat berdasarkan beberapa variabel yang didapat dari Teori Techonology Acceptance Model (TAM) dan ditambah variabel eksternal sesuai dengan hasil penelitian yang dilakukan oleh Susiati (2011). Peneliti juga menambahkan beberapa pertanyaan untuk menggali lebih dalam tentang pemanfaatan e-resources yang disesuaikan dengan keadaan objek penelitian.

\section{Uji Validitas dan Reabilitas}

Pengujian validitas dan reabilitas dalam penelitian ini dilakukan dengan cara membagikan instrumen penelitian yang sudah dibuat oleh peneliti kepada 15 mahasiswa. Selanjutnya, dari hasil jawaban 15 mahasiswa tersebut diuji validitas dan uji reabilitas menggunakan bantuan program SPSS. Berdasarkan pengujian tersebut didapatkan kuesioner sudah valid, sehingga dilanjutkan untuk penelitian.

\section{Metode Analisis Data}

Metode analisis data yang akan digunakan pada penelitian ini adalah statistik inferensial. Statistik inferensial adalah statistik yang digunakan untuk menganalisis data sempel dan hasilnya dapat mewakili dan diberlakukan untuk populasi (Sugiyono, 2011: 148).Selanjutnya, karena penelitian ini menggunakan pendekatan korelasi maka untuk teknik analisisnya adalah dengan melakukan pengujian terhadap hipotesis yang diajukan.Adapun teknik menguji hipotesisnya adalah menggunakan uji korelasi spearman rank. Alasan dipilihnya uji korelasi spearman rank karena pada penelitian ini menguji korelasi dan bentuk datanya bersifat ordinal (Sugiyono, 2011: 153). 


\section{G. PEMBAHASAN}

Dalam penelitian ini kuesioner dibagikan kepada mahasiswa pascasarjana IAIN Salatiga yang terdiri dari 3 program studi, yaitu ekonomi syariah yang berjumalah 22 orang mahasiswa, pendidikan agama islam berjumlah 110 orang mahasiswa dan pendidikan madrasah ibtidaiyyah yang berjumlah 107 orang mahasiswa. Kuesioner dibagikan secara acak melalui laman yang dibagikan ke dalam grup angkatan dan didapatkan responden sebanyak 71 orang. Laki-laki sebanyak 39\%, dan perempuan $61 \%$. Informasi pemanfaatan e-resource terbesar didapatkan dari staff perpustakaan (34\%), dari teman (30\%), dari dosen (18\%), dari media sosial (15\%), dan yang lainnya (3\%) yang menyatakan mengetahui e-resources IAIN Salatiga dari website perpustakaan dan dari kegiatan penelitian yang pernah dilakukan.

Portal e-resource yang paling sering digunakan oleh mahasiswa pascasarjana adalah pustabiblia (93\%), emerald insight (4\%), The MIT Press (1\%), JStor (1\%), dan Ebscohost (1\%). Responden mengakses portal e-resource dengan presentase tertinggi adalah 2 - 3 kali dalam setahun (45\%), 1 kali dalam satu bulan (27\%), 1 kali dua minggu (15\%), dan $2-3$ kali dalam satu minggu (13\%). Mereka lebih menyukai mengakses e-resource ketika di rumah (49.3\%), mengkases dari lingkungan IAIN Salatiga (18.3\%), mengakses dari perpustakaan IAIN Salatiga (16.9\%), mengakses dari kantor mereka bekerja (11.3\%), dan mengakses di manapun (4.2\%). Dalam mengakses e-resource rata-rata responden bertujuan untuk mengerjakan tugas (55\%), mengerjakan thesis (37\%), Mengisi waktu luang (4\%), menyelesaikan laporan penelitian (1\%), dan kesadaran diri (1\%).

Berdasarkan hasil pengujian data diperoleh hasil -0,004 (Tabel 1). Hasil ini belum cukup untuk dapat dikatakan memiliki korelasi. Sehingga dapat disimpulkan bahwa tidak ada pengaruh literasi informasi dengan persepsi kemudahan menggunakan e-resources. Meskipun bisa jadi mahasiswa memiliki literasi informasi akan tetapi belum tentu mereka berpersepsi bahwa e-resources mudah untuk digunakan. 


\section{Tabel 1. Uji korelasi literasi informasi terhadap persepsi kemudahan menggunakan e-resources}

\begin{tabular}{|c|c|c|c|c|}
\hline \multicolumn{5}{|c|}{ Correlations } \\
\hline & & & $\begin{array}{c}\text { Information } \\
\text { Literacy }\end{array}$ & Ease of Use \\
\hline \multirow[t]{6}{*}{ Spearman's rho } & \multirow[t]{3}{*}{ Information Literacy } & Correlation Coefficient & 1.000 & -.004 \\
\hline & & Sig. (2-tailed) & . & .977 \\
\hline & & $\mathrm{N}$ & 71 & 71 \\
\hline & \multirow[t]{3}{*}{ Ease of Use } & Correlation Coefficient & -.004 & 1.000 \\
\hline & & Sig. (2-tailed) & .977 & . \\
\hline & & $\mathrm{N}$ & 71 & 71 \\
\hline
\end{tabular}

Selanjutnya, peneliti juga melakukan pengujian pengaruh literasi informasi terhadap perception of usefulness. Berdasarkan hasil pengujian diperoleh hasil (Tabel 2). Hasil tersebut dapat dikatakan signifikan, sehingga dapat disimpulkan bahwa literasi informasi berpengaruh terhadap perception of usefulness.

\section{Tabel 2. Uji korelasi literasi informasi terhadap persepsi manfaat} e-resources

Correlations

\begin{tabular}{|c|c|c|c|c|}
\hline & & & $\begin{array}{c}\text { Information } \\
\text { Literacy }\end{array}$ & Usefulness \\
\hline \multirow[t]{6}{*}{ Spearman's rho } & \multirow[t]{3}{*}{ Information Literacy } & Correlation Coefficient & 1.000 & $.498^{* *}$ \\
\hline & & Sig. (2-tailed) & . & .000 \\
\hline & & $\mathrm{N}$ & 71 & 71 \\
\hline & \multirow[t]{3}{*}{ Usefulness } & Correlation Coefficient & $.498^{* *}$ & 1.000 \\
\hline & & Sig. (2-tailed) & .000 & . \\
\hline & & $\mathrm{N}$ & 71 & 71 \\
\hline
\end{tabular}

Selain melakukan pengujian terhadap perception ease of use dan perception of usefulness, peneliti juga melakukan pengujian terhadap actual to use atau penggunaan e-resources. Berdasarkan hasil pengujian diperoleh hasil 0,299 (Tabel 3). Hasil tersebut sudah dapat disimpulkan bahwa literasi informasi memiliki pengaruh terhadap persepsi manfaat e-resources. 
Mahasiswa yang memiliki kemampuan literasi informasi memiliki persepsi bahwa e-resouces bermanfaat.

Tabel 3. Uji korelasi literasi informasi terhadap penggunaan $e$-resources

\begin{tabular}{|c|c|c|c|c|}
\hline \multicolumn{5}{|c|}{ Correlations } \\
\hline & & & $\begin{array}{l}\text { Information } \\
\text { Literacy }\end{array}$ & Actual to Use \\
\hline \multirow[t]{6}{*}{ Spearman's rho } & \multirow[t]{3}{*}{ Information Literacy } & Correlation Coefficient & 1.000 & $.299^{*}$ \\
\hline & & Sig. (2-tailed) & . & .011 \\
\hline & & $\mathrm{N}$ & 71 & 71 \\
\hline & \multirow[t]{3}{*}{ Actual to Use } & Correlation Coefficient & $.299^{*}$ & 1.000 \\
\hline & & Sig. (2-tailed) & .011 & \\
\hline & & $\mathrm{N}$ & 71 & 71 \\
\hline
\end{tabular}

${ }^{\star}$. Correlation is significant at the 0.05 level (2-tailed).

Berdasarkan tiga pengujian di atas, literasi informasi belum terbukti memiliki pengaruh terhadap kemudahan penggunaan e-resources. Hasil ini menunjukkan belum lengkapnya pilar literasi informasi khususnya pilar locate and access atau pilar mengetahui bagaimana mengakses sumber infotmasi dan memeriksa alat untuk akses dan temu balik informasi (Sulistyo-Basuki, 2013). Akan tetapi, literasi informasi terbukti memiliki pengaruh terhadap persepsi manfaat dan penggunan e-resources. Mahasiswa yang memiliki kemampuan literasi informasi yang baik sudah merasakan manfaat dari $e$-resources dan sudah menggunakan e-resources.

Melalui literasi informasi, mahasiswa dapat merasakan manfaat dan menggunakan e-resources. Akan tetapi literasi informasi belum dapat menjawab tantangan kesulitan menggunakan e-resources. Maka dari itu, Perpustakaan perlu untuk menyebarkan manfaat dan penggunaan $e$-resources baik melalui user training atau bentuk kegiatan lain. Selain itu user training juga diharapkan dapat mengatasi masalah meningkatkan perception ease of use. Hal ini didasarkan pada penelitian yang dilakukan oleh Susiati yang menyatakan bahwa user training berpengaruh terhadap kemudahan menggunakan jurnal elektronik. (Susiati, 2011: 22). 


\section{H. SIMPULAN}

Berdasarkan pengujian-pengujian yang dilakukan oleh peneliti terhadap empat variabel dengan tiga kali pengujian didapat satu pengujian tidak memiliki pengaruh yaitu literasi informasi terhadap kemudahan penggunaan $e$-resources. Selanjutnya, dua pengujian lainnya menunjukkan adanya pengaruh. Pertama, literasi informasi berpengaruh terhadap perceived of usefulness atau persepsi mengenai kegunaan / manfaat e-resources. Dapat disimpulkan bahwa mahasiswa yang memiliki literasi informasi berpersepsi bahwa e-resources dari Perspustakaan IAIN Salatiga bermanfaat. Kedua, literasi informasi berpengaruh terhadap actual to use atau penggunaan e-resources secara langsung. Mahasiswa IAIN Salatiga yang memiliki kemampuan literasi informasi akan menggunakan $e$-resources yang dilanggan Perpustakaan IAIN Salatiga.

\section{DAFTAR PUSTAKA}

Arikunto, Suharsimi. 2010. Prosedur Penelitian Suatu Pendekatan Praktik. Jakarta: Rineka Cipta.

Ghozali, Imam. 2009. Aplikasi Analisis Multivariate Dengan Program SPSS Edisi Keempat. Semarang: Badan Penerbit Universitas Diponegoro.

Katabalwa, Anajoyce Samuel. 2016. "Use of electronic journal resources by postgraduate students at the University of Dar es Salaam”, dalam Library Review Vol. 65 No. 6/7, 2016 pp. 445-460.

Muhson, Ali. 2016. Teknik Analisis Kuantitatif. http://staffnew.uny.ac.id/ upload/132232818/pendidikan/Analisis+Kuantitatif.pdfdiakses pada 13 Agustus 2020

Nusantari, Dwi Dian. 2012. Analisis pemanfaatan jurnal online Science Direct di Perpustakaan IPB (Studi kasus pada mahasiswa pascasarjana S2 IPB). https://www.researchgate.net/publication/304015081_Analisis_ pemanfaatan_jurnal_online_Sciencedirect_di_Perpustakaan_IPB_ Sudi_Kasus_pada_Mahasiswa_Pascasarjana_IPB

Sevilla C., et.al. 1993. Pengantar Metode Penelitian. Jakarta: UI Press.

Sholihah, Kurnia. 2016. "Analisis Literasi Digital: Studi Pemanfaatan Jurnal E-lektronik oleh Mahasiswa Magister Manajemen di Perpustakaan 
UKSW Salatiga”. Universitas Islam Negeri Sunan Kalijaga Yogyakarta. Sugiyono. 2011. Metode Penelitian Pendidikan: Pendekatan Kuantitatif, Kualitatif, dan R\&D. Bandung: Alfabeta.

-----. 2017. Metode Penelitian Kuantitatif, Kualitatif, dan R\&D. Bandung: Alfabeta.

Sulistyo-Basuki. 2004. Pengantar Dokumentasi. Bandung: Rekayasa Sains.

------. 2006. Metode Penelitian. Jakarta: Wedatama Widya Sastra bekerja sama dengan Fakultas Ilmu Pengetahuan Budaya Universitas Indonesia.

Susiati, Anastasia Tri. 2011. "Pemanfaatan Jurnal Elektronik di Perpustakaan Universitas Atma Jaya Yogyakarta” dalam Berkala Ilmu Perpustakaan dan Informasi, Vol. VII no. 12011, p. 18-24.

Wirartha, I Made. 2006. Pedoman Penulisan Usulan Penelitian, Skripsi dan Tesis. Yogyakarta: Andi.

Igbaria, Magid, et al. "A Motivational Model of Microcomputer Usage." Journal of Management Information Systems, vol. 13, no. 1, 1996, pp. 127143. JSTOR, www.jstor.org/stable/40398206. Accessed 18 Aug. 2020.

Davis, Fred D. "Perceived Usefulness, Perceived Ease of Use, and User Acceptance of Information Technology." MIS Quarterly, vol. 13, no. 3, 1989, pp. 319-340. JSTOR, www.jstor.org/stable/249008.Accessed 18 Aug. 2020.

Sung Youl Park."An Analysis of the Technology Acceptance Model in Understanding University Students' Behavioral Intention to Use e-Learning." Journal of Educational Technology \& Society, vol. 12, no. 3, 2009, pp. 150-162. JSTOR, www.jstor.org/stable/ jeductechsoci.12.3.150.Accessed 18 Aug. 2020.

Venkatesh, Viswanath, and Fred D. Davis. "A Theoretical Extension of the Technology Acceptance Model: Four Longitudinal Field Studies." Management Science, vol. 46, no. 2, 2000, pp. 186-204. JSTOR, www.jstor.org/stable/2634758.Accessed 18 Aug. 2020.

https://sulistyobasuki.wordpress.com/2013/03/25/literasi-informasi-danliterasi-digital/ 